\title{
ВЛИЯНИЕ ХРОМАТОГРАФИЧЕСКИХ УСЛОВИЙ НА ОПРЕДЕЛЕНИЕ ЛИПОФИЛЬНОСТИ ЦНС-АКТИВНЫХ ФАРМАКОЛОГИЧЕСКИХ СРЕДСТВ ВЭЖХ МЕТОДОМ
}

\author{
Д.М. Кочура, Д.В. Криворотов, А.С. Радилов, С.А. Дулов
}

Федеральное государственное унитарное предприятие «Научно-исследовательский институт гигиены, профпатологии и экологии человека» Федерального медико-биологического агентства (ФГУП «НИИ ГПЭЧ» ФМБА России), 188663, Россия, Ленинградская область, Всеволожский район, г.п. Кузьмоловский, ст. Капитолово, корп. №93.

DOI: 10.19163/MedChemRussia2021-2021-266

E-mail: 79117050635@yandex.ru

Показатель липофильности (logP) можно определять ВЭЖХ-методом в соответствии с принципами, отраженными в руководстве ОЭСР: «Partition Coefficient (n-Octanol/Water), High Performance Liquid Chromatography (HPLC) Method» (1989г.).

Целью исследования являлось изучение влияния состава подвижной фазы и влияния типа модифицированного сорбента хроматографической колонки (С8/C18) на качество оценки липофильности ряда известных фармакологических средств ВЭЖХ-методом.

Для построения калибровочной зависимости нами были предложены вещества ионизирующиеся лекарственные средства, с хорошо изученной лиофильностью. В зависимости от комбинации подвижной фазы и хроматографической колонки получили 4 калибровочных зависимостей зависимости $\log \mathrm{P}$ от логарифма коэффициента удерживания стандартных образцов (logk). По полученным калибровочным зависимостям рассчитали коэффициенты распределения для модельных веществ.

\begin{tabular}{|c|c|c|c|c|c|c|c|c|}
\hline \multirow[b]{3}{*}{$\begin{array}{c}\text { Изучаемые } \\
\text { фарм. } \\
\text { средства }\end{array}$} & \multicolumn{8}{|c|}{$\log P$} \\
\hline & \multirow[b]{2}{*}{$\begin{array}{c}\text { справ. } \\
\text { Drug } \\
\text { Bank }^{*}\end{array}$} & \multicolumn{3}{|c|}{ Расчетные значения $\log$ P } & \multicolumn{4}{|c|}{$\begin{array}{c}\text { Полученные значения logP } \\
\text { методом ВЭЖХ }\end{array}$} \\
\hline & & $\begin{array}{c}\text { ACD/ } \\
\text { Percepta }\end{array}$ & ALOGPS & $\begin{array}{l}\text { Chem } \\
\text { Axon }\end{array}$ & $\begin{array}{c}\text { Колонка } \\
\text { С18 } \\
\text { Элюент } \\
\text { МеОН: } \\
\mathrm{H}_{2} \mathrm{O} \\
(1: 3)\end{array}$ & $\begin{array}{c}\text { Колонка } \\
\text { С18 } \\
\text { Элюент } \\
\mathrm{CH}_{3} \mathrm{CN}: \\
\mathrm{H}_{2} \mathrm{O} \\
(3: 17)\end{array}$ & $\begin{array}{c}\text { Колонка } \\
\text { С8 } \\
\text { Элюент } \\
\text { МеОН: } \\
\mathrm{H}_{2} \mathrm{O} \\
(1: 3)\end{array}$ & $\begin{array}{c}\text { Колонка } \\
\text { С8 } \\
\text { Элюент } \\
\text { CH3CN: } \\
\mathrm{H}_{2} \mathrm{O} \\
(3: 17)\end{array}$ \\
\hline налоксон & 2,09 & $1,45 \pm 0,64$ & 1,47 & 1,62 & 1,78 & 1,77 & 1,79 & 1,78 \\
\hline налтрексон & 1,92 & $1,80 \pm 0,55$ & 2,07 & 1,36 & 1,91 & 1,94 & 1,90 & 1,93 \\
\hline апоморфин & 2,00 & $3,05 \pm 0,40$ & 2,51 & 2,87 & 2,18 & 2,14 & 2,14 & 2,12 \\
\hline атропин & 1,83 & $1,53 \pm 0,37$ & 2,19 & 1,57 & 2,22 & 2,22 & 2,20 & 2,18 \\
\hline налмефен & - & $2,65 \pm 0,49$ & 2,24 & 1,95 & 2,36 & 2,36 & 2,30 & 2,34 \\
\hline папаверин & 3,00 & $3,74 \pm 0,50$ & 4,19 & 3,08 & 2,75 & 2,77 & 2,81 & 2,82 \\
\hline дипренорфин & - & $2,21 \pm 0,57$ & 3,52 & 2,28 & 2,77 & 2,84 & 2,67 & 2,70 \\
\hline
\end{tabular}

Анализ результатов показал, что наибольший вклад в уравнение зависимости липофильности от логарифма времени удерживания вносит неподвижная фаза. Для дальнейшего более глубокого изучения процессов, влияющих на определения logP хроматографическим методом, требуется расширять обучающую выборку путем добавления в нее веществ, как с большим, так и с меньшим значением logP.

$$
-266-
$$

